\title{
Yes, science denial is extremely costly, but...
}

\author{
Minh-Hoang Nguyen \\ Ritsumeikan Asia-Pacific University \\ Beppu, Japan \\ ng19m6tk@apu.ac.jp
}

December 29, 2021

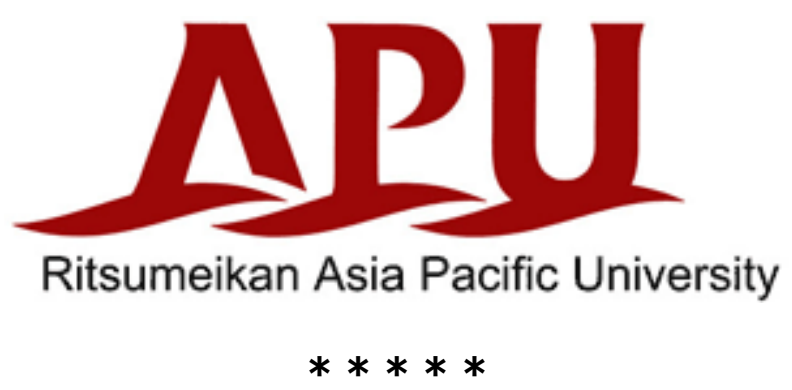

Author Tom Steyer rightly wrote in his article the following words:

"The effects on our planet from Republican climate denial will be much less reversible than the damage caused by that group's inaction on the coronavirus." [1]

And in line with this, science denial caused societies, no matter how developed they are, severe costs. These costs are usually having the form of policy failures [2-3]. While the consideration of the cost of science is both legitimate and worthwhile, it will never be a match to costs caused by policy failures [4], especially when we deal with such life-or-death matters as Covid-19 pandemic or global climate breakdown.

So, yes, science denial is extremely costly, but...

... Simply asking politicians to listen to scientific evidence and turn the datadriven insights into actionable programs is naive. For politicians, the risk-costbenefit considerations are diametrically different to those of the science ivory tower. That's why Horton and Brown [5] had to profess:

"However, a more constructive and positive response would be to realise that the evaluation of scientific evidence cannot be divorced from the political, cultural and social debate that inevitably and justifiably surrounds most major issues. Using the two examples above, the long 
and sometimes tortuous pathway to the COP21 climate change accord results from the difficult economic trade-offs involved and the very different socio-political perspectives of the nations of the world."

Now, we can see that the world is far from resolving this fatal problem of communication deadlocks between science and politics. This is exactly what Boswell and Smith [6] showed concerning the illusions in the mind of many in the academic circle that:

“Notions of 'impact', 'engagement' and 'knowledge exchange' are typically premised on simplistic, linear models of the policy process, according to which policy-makers are keen to 'utilise' expertise to produce more 'effective' policies."

Those who believe in the simplistic trust model between politics and science unintentionally (or intentionally) omit the fact that there exists something called cultural value systems and norms, which govern the formation, growth and demise of a group. These elements are so critical that by setting them aside, we risk entering total disagreements whenever difficult problems arise.

One such serious problem is the climate crisis and the need for building the eleventh cultural value as proposed by Vuong [7]. And this value will complement the progressive value system suggested by Harrison [8].

It is safe to say that besides hard-core sciences, resolving global problems posing existential threats to humankind will certainly require us to deploy our best weapons, and many must come from the social sciences and humanities [9]. Therefore, the future solution to global change problems will have to show us its social heart.

\section{Acknowledgement}

I would like to thank Prof. Vuong Quan Hoang for giving me valuable advice on this essay.

\section{References}

[1] Steyer, T. (2020, March 30). Coronavirus shows the cost of science denial. San Francisco Chronicle. Retrieved from: https://www.sfchronicle.com/opinion/openforum/article/Coronavirusshows-the-cost-of-science-denial-15164303.php

[2] McConnell, A. (2015). What is policy failure? A primer to help navigate the maze. Public Policy and Administration, 30(3-4), 221-242. 
[3] De Mesquita, B. B., Morrow, J. D., Siverson, R. M., \& Smith, A. (1999). Policy failure and political survival: The contribution of political institutions. Journal of Conflict Resolution, 43(2), 147-161.

[4] Vuong, Q. H. (2018). The (ir)rational consideration of the cost of science in transition economies. Nature Human Behaviour, 2(1), 5.

[5] Horton, P., \& Brown, G. W. (2018). Integrating evidence, politics and society: a methodology for the science-policy interface. Palgrave Communications, $4(1), 42$.

[6] Boswell, C., \& Smith, K. (2017). Rethinking policy 'impact': four models of research-policy relations. Palgrave Communications, 3(1), 44.

[7] Vuong, Q. H. (2021). The semiconducting principle of monetary and environmental values exchange. Economics and Business Letters, 10(3), 284-290.

[8] Harrison, L. E. (2000). Culture matters. The National Interest, 60, 55-65.

[9] Mooney, H. A., Duraiappah, A., \& Larigauderie, A. (2013). Evolution of natural and social science interactions in global change research programs. Proceedings of the National Academy of Sciences, 110(S1), 3665-3672.

[10] Hackmann, H., Moser, S. C., \& Clair, A. L. S. (2014). The social heart of global environmental change. Nature Climate Change, 4(8), 653-655. 